\title{
CHRONIC VENOUS INSUFFICIENCY
}

\author{
Antoni Stadnicki \\ Professor, DMedSc, Polonia University in Czestochowa, e-mail: astadnic@wp.pl, \\ orcid.org/0000-0003-2675-3732, Poland \\ Martin Rusnák \\ Professor, MD, CSc, Trnava University, e-mail: martin.rusnak@truni.sk, \\ orcid.org/0000-0003-3321-1042, Slovakia
}

Anna Stadnicka

BA, University of Economics and Innovation in Lublin, e-mail: astadnicka007@gmail.com, orcid.org/0000-0001-5107-8551, Poland

\begin{abstract}
Chronic venous insufficiency (CVI) is a common, but underdiagnozed clinical disorder associated with a variety of signs and symptoms. The presence of leg edema in association with varicose veins, and venous leg ulcer in later disease stages defines the disease. The pathogenesis of chronic venous disease is based on venous reflux, obstruction, or a combination thereof. Prior postthrombotic syndrome is one of risk factor for CVI which may explain observed prevalence of thrombophilia in CVI. Color flow duplex ultrasound is the gold standard for nearly all diagnostic issues related to chronic venous disease. Compression stockings are the mainstay for conservative management. Earlier use of venous ablation therapy should be considered in symptomatic patients with superficial tortuous vein. therapy

Keywords: varicose veins, postthrombotic syndrome, thrombophilia, endovenous laser
\end{abstract}

DOI: $h t t p: / / d x . d o i . o r g / 10.23856 / 3217$

\section{Introduction}

Chronic venous insufficiency (CVI) describes a condition that affects the venous system of the lower extremities including symptoms and sings such as pain, edema, heaviness, noctural cramps, hyperpigmentation, venous eczema, and ulcerations in advanced stages. CVI of the leg is a relatively common but frequently underdiagnosed medical problem (Raju, Neglen, 2009).

\section{Classification}

The CEAP (Clinical-Etiology-Anatomic-Pathophysiologic) system is an excellent classification of chronic venous disease including CVI as more advanced stages in CEAP system (Eklöf, 2006). All six clinical classes of chronic venous disease (C1-C6) are characterized by pathophysiological signs and clinical symptoms, such as presented in modification.

Class C1 shows telangiectases or spider veins.

Class C2 represents small varicose veins, but without clinical signs of CVI.

Class C3 defines the onset of CVI with presence of leg edema, and may persist in untreated cases with varicose veins. 
C4 class demonstrates constant leg edema, varicose veins with trophic skin lesions, purpura and eczema.

Class C5 indicates healed leg ulcer e.g. showing improvement.

Class C6 ulcers stable or increase.

In addition., Widmer's classification is simple and useful for CVI (table 1)

Table 1

\section{Modified Widmer's classification of chronic venous insufficiency}

\begin{tabular}{|c|l|}
\hline Stage 1 & Few varices, reversible edema limited to foot and ankle \\
\hline Stage 2 & Varices, atrophie blanche, persistent edema extended above ankle \\
\hline Stage 3a & Healed leg ulcer \\
\hline Stage 3b & Active leg ulcer \\
\hline
\end{tabular}

\section{Risk factors}

The reported prevalence of chronic venous disease and CVI shows variability, depending on classification.and the study population, however, varicose veins (CEAP stage C2-C3) are demonstrated approximately $25 \%$ of the population, whereas trophic alterations including ulcers (CEAP stage C4-C6) up to $5 \%$ of population (Evans, et al., 1999). The prevalence of CVI in Western population is expected to increase, given the possible underdiagnose of CVI, the increase is considered in obesity and an aging population (Fowkes, et al., 2001; Moura, et al., 2010). Other risk factors include sedentary lifestyle, prolonged standing, lower extremity trauma, prior venous thrombosis, high estrogen states, pregnancy, smoking (Callam, 1994).

\section{Pathophysiology}

The pathophisiology of CVI is not entirely clear. The most common cause of CVI is superficial insufficiency of venous valve, which are required to provide blood return from the lower extremities. Venous hypertension is caused by venous valve reflux, venous flow obstruction, or both (Eberhardt, Raffetto, 2014). If valves veins are incompetent, the high pressures generated in the deep veins by calf-muscle contraction can be transmitted to the superficial system and to the microcirculation in skin. Venous hypertension results in red cells extravasation and hyperpigmentation. Inflammation is thought to play a role as well as damage to the venous valves from the thrombus itself (Raffetto, Mannello, 2014). CVI may be involved in superficial vein thrombosis (Barron, et al., 2007). However CVI may be caused by deep vein thrombosis, and subsequent acute sings and symptoms described as postthrombotic syndrome, also called postphlebitic syndrome (Tick, 2008).

In pathphysiology of postthrombotic syndrome (PTS) inflammation as well as damage to the venous valves from the thrombus itself is thought to play a role. This valvular incompetence combined with persistent venous obstruction from thrombus increases the pressure in veins and capillaries, thus postthrombotic syndrome is risk factor for CVI. Since signs and symptoms of deep vein thrombosis and PTS may be quite similar, a diagnosis of PTS should be delayed for 3-6 months after deep venous thrombosis diagnosis. Deep venous thrombosis is caused mainly by thrombophilia, inherited or acquired alterations of coagulation or fibrinolysis turn to hypercoagulability. Although malignancy and major surgery are 
associated with deep venous thrombosis, this condition may be caused by the chronic diseases like nephritic, syndrome, autoimmune disorders or first of all other various chronic states prone to hypercoagulability such as an immobilization, oral contraceptive use or hyperhomocysteinemia due to a deficiency of B12, B6 and folate in the diet. It is also indicated to screen for hereditary genetic abnormalities mainly anticoagulant protein $\mathrm{C}$, and protein S deficiency, factor V Leiden, and the genetic variant prothrombin G20210A, especially if venous thrombosis develops in earlier age. Taken together CVI features as venous reflux and obstruction may frequently develop secondary to deep venous thrombosis and postthrombotic syndrome. Some studies have indicated the prevalence of thrombophilia also in patients with CVI showing that the increased prevalence of thrombophilia in patients with CVI and advanced varicose veins is similar to that observed in patients after deep venous thrombosis (Bradbury, et al., 2002). Macrovascular and microvascular venous leg thrombosis may have significance in development of CVI.

\section{Clinical features}

It should be noted that the presence of leg edema, initially spontaneously reversible overnight but later on may persist, in association with varicose veins (class C3) defines the onset of CVI (Santler, Goerge, 2017).Clinical features of CVI include discomfort, swelling, varicose veins, and skin changes Venous leg discomfort is often described as a dull ache, throbbing or "heavy legs" especially after prolonged standing, and is relieved by elevation of the leg or walking. .Leg edema is a common feature of CVI. It should be underlined that bilateral leg edema can be also caused by congestive heart failure, hypoalbuminemia secondary to nephrotic syndrome or severe hepatic disease, myxedema during hypothyroidism. During CVI may develop secondary lymphedema, however it may resolve if CVI is improved. Varicose veins are dilated, superficial veins, measuring at least $3 \mathrm{~mm}$ in diameter that become progressively more tortuous and enlarged. Patients with varicose veins are often asymptomatic, but they may cause pain if superficial thrombophlebitis develops.

\section{Diagnosis}

Diagnostically Doppler ultrasound may be employed as a screening test for chronic venous disease. Doppler ultrasould can detect venous obstruction or valvular incompetence (McMullin, 1992). However color flow duplex ultrasound is the gold standard for nearly all diagnostic issues related to chronic venous disease. Clots in the leg veins can be accurately diagnosed by compressing the veins with the ultrasound probe (Goodacre, et al., 2005). Computed tomography (CT) and magnetic resonance (MR) images have allowed for better evaluation of venous disease, although these techniques do not provide functional information.

\section{Treatment}

Medical compression therapy is the basis of any treatment of chronic venous disease, although the compression therapy of is useful only in preventing a worsening of this condition. It is relatively easy to use, noninvasive. This may include compression stockings, sequential compression pump, and manual compression lymphatic massage therapy. It play a role in relieving symptoms and edema in the legs (Motykie, et al., 1999). Compression 
therapy should apply moderate pressure (20 to $30 \mathrm{mmHg}$ ) for patients with varicose veins who are not qualified endovenous ablation. However compression therapy is especially important in the treatment of healing leg ulcers (Dissemond, et al., 2016). Despite the clinical effectiveness of compression stockings, there are many limitations to their application, including poor compliance. Many of patients cannot continue compression therapy (Raju, et al., 2007). In addition kinesitherapy in the form of exercises with elevated lower limbs, isometric exercises of leg muscles, swimming and walking is beneficial. Kinesitherapy is indicated only six months after treatment of venous thrombosis, and without leg ulcers (CEAP class $\mathrm{C} 5$ and $\mathrm{C} 6$ ).

Medical therapy of CVI has still not efficient. Many compounds have been tried for the treatment of symptomatic varicose veins such as a saponins, rutosides, diosmin (Guilhou, et al., 1997). New approaches for prevention of CVI could be related to thrombophilia as an important risk factor for the development of CVI and varicose veins. Some reports have indicated a beneficial effect of warfarin (Brandt, Messina, 2007) and aspirin (Ibbotson, Layton, 1997) in therapy of chronic venous ulcers associated with thrombofilia. The aim of surgical and endovenous procedures in chronic venous disease is to remove obliterate veins. Surgical treatments for CVI include ligation procedures, vein stripping, endovenous laser ablation (Bohler, 2016). Surgical therapy of varicose veins with high ligation and stripping of the great saphenous vein combined with the excision of large varicose veins has been long time the standard. However at present there is commonly used endovenous thermal treatment e.g. radiofrequency ablation and endovenous laser therapy of dilated and tortuous saphenous vein, which are comparable to the postoperative outcome following saphenofemoral ligation and stripping (Stoughton, 2011). In earlier stages minimally invasive surgery strategic for the treatment of varicose veins is performed under local anaesthetic (Neser, et al., 2011).

\section{References}

Barron, G. S., Jacob, S. E., Kirsner RS (2007). Dermatologic complications of chronic venous disease: medical management and beyond. Ann Vasc Surg 21, (5), 652-62. [in English]. Bohler, K. (2016). Surgery of varicose vein insufficiency. Wien Med Wochenschr, 166 (9-10), 293-6. DOI: 10.1007/s10354-016-0486-6. [in German].

Bradbury, A. W., MacKenzie, R. K., Burns, P., Fegan, C. (2002). Thrombophilia andchronic venous ulceration. European Journal of Vascular and Endovascular Surgery, 24, 97-104. [in English].

Brandt, H. R. C., Messina, M. C. D., Belda, W., Jose, E. C. M., Criado, P. R. (2007). Leg ulcers associated with factor V Leiden and prothrombin G20210A and methyltetrahydrofolate reductase mutations: successful treatment with warfarin. International Journal of Dermatology, 46 (12), 1319-20. DOI: 10.1111/j.1365-4632.2007.03424.x. [in English].

Callam, M. J. (1994). Epidemiology of varicose veins. British Journal of Surgery, 81,167173. [in English].

Dissemond, J., Assenheimer, B., Bultemann, A., et al. (2016). Compression therapy in patients with venous leg ulcers. Journal der Deutschen Dermatologischen Gesellschaft, 14, 1072-87. DOI: 10.1111/ddg.13091. [in English].

Eberhardt, R. T., Raffett,o J. D. (2014). Chronic venous insufficiency. Circulation, 130, 333346. [in English].

Eklöf, B. (2006). CEAP classification and implications for investigations. Acta chirurgica Belgica, 106 (6), 654-8. [in English]. 
Eklöf, B., Rutherford, R. B., Bergan, J. J., Carpentier, P. H., Gloviczki, P. et al. (2004). Revision of the CEAP classification for chronic venous disorders: consensus statement. American Venous Forum International Ad Hoc Committee for Revision of the CEAP Classificatioion. Journal of vascular surgery, $40 \quad$ (6), 1248-52. DOI:10.1016/j.jvs.2004.09.027. [in English].

Evans, C. J., Fowkes, F. G., Ruckley, C. V., Lee, A. J. (1999). Prevalence of varicose veins and chronic venous insufficiency in men and women in the general population: Edinburgh Vein Study. The Journal of Epidemiology and Community Health, 53, (3), 149-53. [in English].

Fowkes, F. G., Lee, A. J., Evans, C. J., Allan, P. L., Bradbury, A. W., Ruckley, C. V. (2001). Lifestyle risk factors for lower limb venous reflux in the general population: Edinburgh Vein Study. International Journal of Epidemiology, 30, 846-852. [in English].

Galanaud, J. P., Holcroft, C. A., Rodger, M. A., et al. (2013) Predictors of postthrombotic syndrome in a population with a first deep vein thrombosis and no primary venous insufficiency. Journal of Thrombosis and Haemostasis, 11, 474-80. [in English].

Goodacre, S., Sampson, F., Thomas, S. et al. (2005). Systematic review and meta analysis of the diagnostic accuracy of ultrasonography for deep vein thrombosis. BMC Med Imaging, 5, 6. [in English].

Guilhou, J.J., Dereure, O., Marzin, L., et al .(1997). Efficacy of Daflon $500 \mathrm{mg}$ in venous leg ulcer healing: a double-blind, randomized, controlled versus placebo trial in 107 patients. Angiology, 48, 77-85. [in English].

Ibbotson, S. H., Layton, A. M., Davies, J. A., Goodfield, M. J. (1995). The effect of aspirin on haemostatic activity in the treatment of chronic venous ulceration. British Journal Dermatol, 132:422-6. [in English].

McMullin, G. M., Coleridge Smith, P. D. (1992). An evaluation of Doppler ultrasound and photoplethysmography in the investigation of venous insufficiency. NZ Journal of Surg, 62, 270-5. [in English].

Motykie, G. D., Caprini, J. A., Arcelus, J. I, et al. (1999). Evaluation of therapeutic compression stockings in the treatment of chronic venous insufficiency. Dermatol Surg, 25, 116-20. [in English].

Moura, R. M., Goncalves, G. S., Navarro, T. P. et al. (2010). Relationship between quality of life and the CEAP clinical classification in chronic venous disease. Rev Bras Fisioter, 14, 99105. [in English].

Neser, R. A., Caffaro, R. A. (2011). Invagination stripping with ultrasound guided perivenous tumescence: an original method of great saphenous vein stripping. Dermatol Surg, 37, 34952. [in English].

Raffetto, J. D., Mannello, F. (2014). Pathophysiology of chronic venous disease. Int Angiol, 33, 212-21. [in English].

Raju, S, Neglen, P. (2009). Clinical practice. Chronic venous insufficiency and varicose veins. The New England Journal of Medicine, 360, 2319-2327. [in English].

Raju, S., Hollis, K., Neglen, P. (2007). Use of compression stockings in chronic venous disease: patient compliance and efficacy. Ann Vasc Surg, 21, 790-795. [in English].

Reitsma, P.H., Versteeg, H.H., Middeldorp, S. (2012). Mechanistic view of risk factors for venous thromboembolism. Arterioscler Thromb Vasc Biol, 32, (3), 563-8. [in English].

Stoughton, J. (2011). Venous ablation therapy: indications and outcomes. Prog Cardiovasc Dis, 54, 61-9. [in English]. 
Tick, L.W., Kramer, M. H., Rosendal, F. R., Faber, W. R., Doggen, C. J. (2008). Risk factors for post-thrombotic syndrome in patients with a first deep venous thrombosis. Journal Thromb Haemost, 6, 2075-81. [in English]. 